Kong. Res. J. 2(1) : 47-49, 2015

ISSN 2349-2694

Kongunadu Arts and Science College, Coimbatore.

\title{
ON TOTALLY SUPRA N-CONTINUOUS FUNCTION AND TOTALLY SUPRA N-CLOSED MAP
}

\author{
Vidyarani, L. and M. Vigneshwaran* \\ Department of Mathematics, Kongunadu Arts and Science College(Autonomous), Coimbatore-641029, \\ Tamilnadu, India. \\ *E.mail: vignesh.mat@gmail.com
}

ABSTRACT

In this paper, we introduce the concept of totally supra $\mathrm{N}$-continuous function and totally supra $\mathrm{N}$-closed map and investigated the relationship of these functions with other functions.

Mathematics subject Classification: 54C05, 54C10.

Keywords: Totally supra N-continuous function, totally supra N-closed map.

\section{INTRODUCTION}

In 1983, Mashhour et al. (1983) introduced the notion of supra topological spaces and studied, continuous functions and $s^{*}$-continuous functions. Jamal M.Mustafa (2012) introduced and studies a class of functions called totally supra b-continuous and slightly supra b-continuous functions in supra topological spaces.

In this paper, we introduce the concept of totally supra $\mathrm{N}$-continuous function and totally supra $\mathrm{N}$-closed map and investigated the relationship of these functions with other functions in supra topological spaces.

\section{PRELIMINARIES}

Definition 2.1(Mashhour et al.,1983) on $\mathrm{X}$ if

A subfamily $\mu$ of $X$ is said to be supra topology

i) $X, \phi \in \mu$

ii) If $A_{i} \in \mu \forall i \in j$ then $\cup A_{i} \in \mu$. The pair $(\mathrm{X}, \mu)$

is called supra topological space.

The element of $\mu$ are called supra open sets in $(\mathrm{X}, \mu)$ and the complement of supra

open set is called supra closed sets and it is denoted by $\mu^{\mathrm{c}}$.

Definition 2.2 (Mashhour et al., 1983)

The supra closure of a set $A$ is denoted by cl $\mu$ (A), and is defined as supra $\operatorname{cl}(\mathrm{A})=\cap\{\mathrm{B}: \mathrm{B}$ is supra closed and $\mathrm{A} \subseteq \mathrm{B}\}$.

The supra interior of a set $A$ is denoted by $\operatorname{int} \mu(\mathrm{A})$, and is defined as $\operatorname{supraint}(A)=U$

$\{B: B \quad$ is supra open and $A \supseteq B\}$.
Definition 2.3 (Mashhour et al., 1983) Let (X, $\tau$ ) be a topological space and $\mu$ be a supra topology on $X$. We call $\mu$ a supra topology associated with $\tau$, if $\tau \subseteq \mu$.

Definition 2.4 Let $(X, \mu)$ be a supra topological space. A set $A$ of $X$ is called

(i) supra semi- open set (Levine, 1991), if $A \subseteq$ $\operatorname{cl} \mu(\operatorname{int} \mu(\mathrm{A}))$.

(ii) supra $\alpha$-open set (Devi et al., 2008), if A $\subseteq$ $\operatorname{int} \mu(\operatorname{cl} \mu(\operatorname{int} \mu(A)))$.

(iii) supra $\Omega$ closed set (Noiri and Sayed, 2005), if $\operatorname{scl} \mu(A) \subseteq \operatorname{int} \mu(U)$,whenever $A \subseteq U, U$ is supra open set.

(iv) supra $\mathrm{N}$-closed set (Vidyarani and Vigneshwaran, 2013), if $\Omega \operatorname{cl} \mu(A) \subseteq U$, whenever $A \subseteq$ $\mathrm{U}, \mathrm{U}$ is supra $\alpha$ open set.

The complement of above supra closed set is supra open and vice versa.

\section{Definition 2.5}

A map $\mathrm{f}:(\mathrm{X}, \tau) \rightarrow(\mathrm{Y}, \sigma)$ is said to be

(i) supra $\mathrm{N}$-continuous (Vidyarani and Vigneshwaran, 2013a), if $f^{-1}(V)$ is supra $N$ closed in $(X, \tau)$ for every supra closed set $V$ of $(\mathrm{Y}, \sigma)$.

(ii) Perfectly supra $\mathrm{N}$-continuous (Vidyarani and Vigneshwaran, 2013a), if $\mathrm{f}^{-1}(\mathrm{~V})$ is supra clopen in $(X, \tau)$ for every supra $N$-closed set $V$ of $(Y, \sigma)$.

(iii) strongly supra $\mathrm{N}$-continuous (Vidyarani and Vigneshwaran, 2013a), if $\mathrm{f}^{-1}(\mathrm{~V})$ is supra closed in $(X, \tau)$ for every supra $\mathrm{N}$-closed set $\mathrm{V}$ of $(\mathrm{Y}$, $\sigma)$.

(iv) supra N-closed map (Vidyarani and Vigneshwaran, 2013b), if $f(V)$ is supra $N$ closed in $(Y, \sigma)$ for every supra closed set $V$ of $(X, \tau)$. 
(v) strongly supra $\mathrm{N}$-closed map (Vidyarani and Vigneshwaran, 2013b), if $f(V)$ is supra $N$ closed in $(Y, \sigma)$ for every supra $\mathrm{N}$-closed set $\mathrm{V}$ of $(X, \tau)$.

\section{TOTALLY SUPRA N-CONTINUOUS FUNCTIONS}

Definition 3.1 A map $\mathrm{f}:(\mathrm{X}, \tau) \rightarrow(\mathrm{Y}, \sigma)$ is called totally supra continuous function if the inverse image of every supra open set in $(Y, \sigma)$ is supra clopen in $(X, \tau)$.

Definition 3.2 A map $\mathrm{f}:(\mathrm{X}, \tau) \rightarrow(\mathrm{Y}, \sigma)$ is called totally supra $\mathrm{N}$-continuous function if the inverse image of every supra open set in $(Y, \sigma)$ is supra $\mathrm{N}$ clopen in $(X, \tau)$.

Theorem 3.3 Every strongly supra N-continuous function is totally supra $\mathrm{N}$-continuous function.

Proof Let $\mathrm{f}:(\mathrm{X}, \tau) \rightarrow(\mathrm{Y}, \sigma)$ be a strongly supra $\mathrm{N}$ continuous function. Let $\mathrm{V}$ be supra open set in $(\mathrm{Y}$, $\sigma)$. Then $\mathrm{V}$ is supra $\mathrm{N}$-open set in $(\mathrm{Y}, \sigma)$, since every supra open set is supra $\mathrm{N}$-open set. Since $\mathrm{f}$ is strongly supra $\mathrm{N}$-continuous function $\mathrm{f}^{-1}(\mathrm{~V})$ is both supra open and supra closed in $(X, \tau)$. Implies $f^{-1}(V)$ is supra $\mathrm{N}$-clopen in $(X, \tau)$. Therefore $f$ is totally supra $\mathrm{N}$-continuous function.

The converse of the above theorem need not be true. It is shown by the following example.

Example 3.4 Let $\mathrm{X}=\mathrm{Y}=\{\mathrm{a}, \mathrm{b}, \mathrm{c}\}$ and $\tau=\{\mathrm{X}, \varphi$, $\{a\},\{b\},\{a, b\},\{b, c\}\}, \sigma=\{Y, \varphi,\{a\}\}$. N-closed set in $(X$, $\tau)$ are $\{X, \varphi,\{a\},\{b\},\{a, b\},\{b, c\}\}$. N-closed set in $(Y, \sigma)$ are $\{Y, \varphi,\{a\},\{b\},\{c\},\{a, b\},\{b, c\},\{a, c\}\} . f:(X, \tau) \rightarrow(Y, \sigma)$ be the function defined by $f(a)=a, f(b)=c, f(c)=b$. Here $f$ is totally supra $\mathrm{N}$-continuous but not strongly supra $\mathrm{N}$-continuous, since $\mathrm{V}=\{\mathrm{a}, \mathrm{c}\}$ is supra $\mathrm{N}$-closed in $(Y, \sigma)$ but $\mathrm{f}^{-1}(\{\mathrm{a}, \mathrm{c}\})=\{\mathrm{a}, \mathrm{b}\}$ is supra open but not supra closed set in $(X, \tau)$.

Theorem 3.5 Every totally supra $\mathrm{N}$-continuous function is supra $\mathrm{N}$-continuous function.

Proof Let $\mathrm{f}:(\mathrm{X}, \tau) \rightarrow(\mathrm{Y}, \sigma)$ be a totally supra $\mathrm{N}$ continuous function. Let $\mathrm{V}$ be supra open set in $(\mathrm{Y}$, $\sigma)$. Since $\mathrm{f}$ is totally supra $\mathrm{N}$-continuous function, then $f^{-1}(V)$ is supra $N$-clopen in $(X, \tau)$. Implies $f$ ${ }^{1}(\mathrm{~V})$ is supra $\mathrm{N}$-open in $(\mathrm{X}, \tau)$. Therefore $\mathrm{f}$ is supra $\mathrm{N}$ continuous function.

The converse of the above theorem need not be true. It is shown by the following example.

Example 3.6 Let $\mathrm{X}=\mathrm{Y}=\{\mathrm{a}, \mathrm{b}, \mathrm{c}\}$ and $\tau=\{\mathrm{X}, \varphi$, $\{a\},\{b\},\{a, b\},\{b, c\}\}, \sigma=\{Y, \varphi,\{a\},\{b, c\}\}$. N-closed set in $(X, \tau)$ are $\{X, \varphi,\{a\},\{b\},\{a, b\},\{b, c\}\}$. N-closed set in $(\mathrm{Y}, \sigma)$ are $\{\mathrm{Y}, \varphi,\{\mathrm{a}\},\{\mathrm{b}\},\{\mathrm{c}\},\{\mathrm{a}, \mathrm{b}\},\{\mathrm{b}, \mathrm{c}\},\{\mathrm{a}, \mathrm{c}\}\} . \mathrm{f:}(\mathrm{X}, \tau) \rightarrow$ $(Y, \sigma)$ be the function defined by $f(a)=c, f(b)=b$, $\mathrm{f}(\mathrm{c})=\mathrm{a}$. Here $\mathrm{f}$ is supra $\mathrm{N}$-continuous but not totally supra $\mathrm{N}$-continuous, since $\mathrm{V}=\{\mathrm{a}\}$ is supra open in $(Y, \sigma)$ but $f^{-1}(\{a\})=\{c\}$ is supra N-closed but not supra $\mathrm{N}$-open set in $(\mathrm{X}, \tau)$.

Theorem 3.7 Every totally supra continuous function is supra $\mathrm{N}$-continuous function.

Proof Let $f:(X, \tau) \rightarrow(Y, \sigma)$ be a totally supra continuous function. Let $\mathrm{V}$ be supra open set in $(\mathrm{Y}$, $\sigma)$. Since $f$ is totally supra continuous function, then $f$ ${ }^{-1}(V)$ is supra clopen in $(X, \tau)$. Implies $f^{-1}(V)$ is supra $\mathrm{N}$-clopen in $(X, \tau)$. Hence $\mathrm{f}^{-1}(\mathrm{~V})$ is supra $\mathrm{N}$-open in $(X, \tau)$. Therefore $\mathrm{f}$ is supra $\mathrm{N}$-continuous function.

The converse of the above theorem need not be true. It is shown by the following example.

Example 3.8 Let $\mathrm{X}=\mathrm{Y}=\{\mathrm{a}, \mathrm{b}, \mathrm{c}\}$ and $\tau=\{\mathrm{X}, \varphi$, $\{a\},\{b\},\{a, b\},\{b, c\}\}, \sigma=\{Y, \varphi,\{a\},\{b, c\}\}$. N-closed set in $(X, \tau)$ are $\{X, \varphi,\{a\},\{b\},\{a, b\},\{b, c\}\}$. N-closed set in $(Y, \sigma)$ are $\{Y, \varphi,\{a\},\{b\},\{c\},\{a, b\},\{b, c\},\{a, c\}\} . f:(X, \tau) \rightarrow$ $(Y, \sigma)$ be the function defined by $f(a)=c, f(b)=b$, $f(c)=a$. Here $f$ is supra $N$-continuous but not totally supra continuous, since $V=\{b, c\}$ is supra open in $(Y, \sigma)$ but $f^{-1}(\{b, c\})=\{a, b\}$ is supra open but not supra closed set in $(X, \tau)$.

Theorem 3.9 Every totally supra continuous function is totally supra $\mathrm{N}$-continuous function.

Proof Let $\mathrm{f}:(\mathrm{X}, \tau) \rightarrow(\mathrm{Y}, \sigma)$ be a totally supra continuous function. Let $\mathrm{V}$ be supra open set in $(\mathrm{Y}$, $\sigma$ ). Since $f$ is totally supra continuous function, then $f$ ${ }^{-1}(\mathrm{~V})$ is supra clopen in $(\mathrm{X}, \tau)$. Implies $\mathrm{f}^{-1}(\mathrm{~V})$ is supra $\mathrm{N}$-clopen in $(X, \tau)$. Therefore $f$ is totally supra $\mathrm{N}$ continuous function.

The converse of the above theorem need not be true. It is shown by the following example.

Example 3.10 Let $X=Y=\{a, b, c\}$ and $\tau=\{X, \varphi,\{a\}\}, \sigma$ $=\{\mathrm{Y}, \varphi,\{\mathrm{a}\},\{\mathrm{b}\},\{\mathrm{a}, \mathrm{b}\},\{\mathrm{b}, \mathrm{c}\}\} . \quad \mathrm{N}$-closed set in $(\mathrm{X}$, $\tau)$ are $\{X, \varphi,\{a\},\{b\},\{c\},\{a, b\},\{b, c\},\{a, c\}\}$. N-closed set in $(Y, \sigma)$ are $\{Y, \varphi,\{a\},\{b\},\{b, c\},\{a, c\}\} . f:(X, \tau) \rightarrow(Y, \sigma)$ be the function defined by $f(a)=b, f(b)=a, f(c)=c$. Here $\mathrm{f}$ is totally supra $\mathrm{N}$-continuous but not totally supra continuous, since $\mathrm{V}=\{\mathrm{a}, \mathrm{b}\}$ is supra open in $(\mathrm{Y}$, $\sigma)$ but $\mathrm{f}^{-1}(\{\mathrm{a}, \mathrm{b}\})=\{\mathrm{a}, \mathrm{b}\}$ is not supra clopen set in $(\mathrm{X}$, $\tau)$.

Theorem 3.11 If $\mathrm{f}:(\mathrm{X}, \tau) \rightarrow(\mathrm{Y}, \sigma)$ is totally supra $\mathrm{N}$ continuous and $\mathrm{g}:(\mathrm{Y}, \sigma) \rightarrow(\mathrm{Z}, \eta)$ is supra continuous then gof: $(X, \tau) \rightarrow(Z, \eta)$ is totally supra $N$-continuous.

Proof Let V be supra open set in Z. Since $g$ is supra continuous, then $g^{-1}(V)$ is supra open set in Y. Since $f$ is totally supra $\mathrm{N}$-continuous, then $\mathrm{f}^{-1}\left(\mathrm{~g}^{-1}(\mathrm{~V})\right)$ is supra $\mathrm{N}$-clopen in $\mathrm{X}$. Hence gof is totally supra $\mathrm{N}$ continuous. 
Theorem 3.12 If $\mathrm{f}:(\mathrm{X}, \tau) \rightarrow(\mathrm{Y}, \sigma)$ is perfectly supra $\mathrm{N}$-continuous and $\mathrm{g:}(\mathrm{Y}, \sigma) \rightarrow(\mathrm{Z}, \eta)$ is totally supra $\mathrm{N}$ continuous then gof: $(X, \tau) \rightarrow(Z, \eta)$ is totally supra $N$ continuous.

Proof Let V be supra open set in Z. Since g is totally supra $\mathrm{N}$-continuous, then $\mathrm{g}^{-1}(\mathrm{~V})$ is supra $\mathrm{N}$-closed and supra $\mathrm{N}$-open set in $\mathrm{Y}$. Since $\mathrm{f}$ is perfectly supra $\mathrm{N}$-continuous, then $\mathrm{f}^{-1} \mathrm{~g}^{-1}(\mathrm{~V})$ is supra clopen in $\mathrm{X}$. Implies $f^{-1} g^{-1}(V)$ is supra $N$-clopen in $X$. Hence gof is totally supra $\mathrm{N}$-continuous.

\section{TOTALLY SUPRA N-CLOSED MAP}

Definition 4.1 A map $\mathrm{f}:(\mathrm{X}, \tau) \rightarrow(\mathrm{Y}, \sigma)$ is said to be totally supra $\mathrm{N}$-closed map, if $\mathrm{f}(\mathrm{V})$ is supra clopen in $(Y, \sigma)$ for every supra $N$-closed set $V$ of $(X, \tau)$.

Theorem 4.2 Every totally supra $\mathrm{N}$-closed map is supra N-closed map.

Proof Let $f:(X, \tau) \rightarrow(Y, \sigma)$ be a totally supra $N$ closed map. Let $V$ be supra closed set in $(X, \tau)$, then $V$ is supra $N$-closed set in $(X, \tau)$, since every supra closed set is supra $\mathrm{N}$-closed set. Since $\mathrm{f}$ is totally supra $N$-closed map, then $f(V)$ is supra clopen in $(Y$, $\sigma)$. Implies $f(V)$ is supra closed in $(Y, \sigma)$. Therefore $f(V)$ is supra $N$-closed in $(Y, \sigma)$. Therefore $f$ is supra $\mathrm{N}$-closed map.

The converse of the above theorem need not be true. It is shown by the following example.

Example 4.3 Let $X=Y=\{a, b, c\}$ and $\tau=\{X, \varphi,\{a, b\}\}, \sigma$ $=\{\mathrm{Y}, \varphi,\{\mathrm{a}, \mathrm{b}\},\{\mathrm{b}, \mathrm{c}\}\}$. N-closed set in $(\mathrm{X}, \tau)$ are $\{\mathrm{X}, \varphi$, $\{c\},\{a, c\},\{b, c\}\}$. N-closed set in $(Y, \sigma)$ are $\{Y, \varphi$, $\{\mathrm{a}\},\{\mathrm{c}\},\{\mathrm{a}, \mathrm{c}\}\}$. $\mathrm{f}:(\mathrm{X}, \tau) \rightarrow(\mathrm{Y}, \sigma)$ be the function defined by $f(a)=c, f(b)=b, f(c)=a$. Here $f$ is supra $N$ closed map but not totally supra $\mathrm{N}$-closed map, since $V=\{b, c\}$ is supra $N$-closed in $(X, \tau)$ but $f(\{b, c\})$ $=\{\mathrm{a}, \mathrm{b}\}$ is supra open but not supra closed set in $(\mathrm{Y}$, $\sigma)$.

Theorem 4.4 Every totally supra N-closed map is strongly supra $\mathrm{N}$-closed map.

Proof Let $\mathrm{f}:(\mathrm{X}, \tau) \rightarrow(\mathrm{Y}, \sigma)$ be a totally supra $\mathrm{N}$ closed map. Let $\mathrm{V}$ be supra $\mathrm{N}$-closed set in $(\mathrm{X}, \tau)$. Since $f$ is totally supra N-closed map, then $f(V)$ is supra clopen in $(Y, \sigma)$. Implies $f(V)$ is supra closed in $(Y, \sigma)$. Therefore $f(V)$ is supra $N$-closed in $(Y, \sigma)$. Therefore $\mathrm{f}$ is strongly supra $\mathrm{N}$-closed map.

The converse of the above theorem need not be true. It is shown by the following example.
Example 4.5 Let $\mathrm{X}=\mathrm{Y}=\{\mathrm{a}, \mathrm{b}, \mathrm{c}\}$ and $\tau=\{\mathrm{X}, \varphi,\{\mathrm{a}\},\{\mathrm{a}, \mathrm{b}\}\}$ ,$\sigma=\{\mathrm{Y}, \varphi,\{\mathrm{a}\},\{\mathrm{c}\},\{\mathrm{a}, \mathrm{c}\}\}$. N-closed set in $(\mathrm{X}, \tau)$ are $\{\mathrm{X}$, $\varphi,\{b\},\{c\},\{a, c\},\{b, c\}\}$. N-closed set in $(Y, \sigma)$ are $\{Y, \varphi$, $\{a\},\{b\},\{c\},\{a, b\},\{b, c\}\}$. f: $(X, \tau) \rightarrow(Y, \sigma)$ be the function defined by $f(a)=a, f(b)=c, f(c)=b$. Here $f$ is strongly supra $\mathrm{N}$-closed map but not totally supra $\mathrm{N}$ closed map, since $V=\{b\}$ is supra $N$-closed in $(X, \tau$ ) but $f(\{b\})=\{c\}$ is supra open but not supra closed set in $(Y, \sigma)$.

Theorem 4.6 If $\mathrm{f}:(\mathrm{X}, \tau) \rightarrow(\mathrm{Y}, \sigma)$ is totally supra $\mathrm{N}$ closed map and $\mathrm{g:}(\mathrm{Y}, \sigma) \rightarrow(\mathrm{Z}, \eta)$ is totally supra $\mathrm{N}$ closed map then gof: $(X, \tau) \rightarrow(Z, \eta)$ is totally supra $N$ closed map.

Proof Let $V$ be supra N-closed set in $X$, then $f(V)$ is supra clopen in $\mathrm{Y}$, since $\mathrm{f}$ is totally supra $\mathrm{N}$-closed map. Implies $f(V)$ is supra closed in $Y$. Then $f(V)$ is supra $\mathrm{N}$-closed in $\mathrm{Y}$, since every supra closed set is supra N-closed set. Since $\mathrm{g}$ is totally supra N-closed map $g(f(V))$ is supra clopen in Z. Hence gof is totally supra $\mathrm{N}$-closed map.

\section{REFERENCES}

Devi, R., S. Sampathkumar and M. Caldas, (2008). On supra $\alpha$ open sets and s $\alpha$-continuous maps, Gen. Math. 16(2): 77-84.

Jamal M. Mustafa, (2012). Totally supra b-continuous and slightly supra b-continuous functions, stud. Univ. Babes. Bolyai Math. 57(1): 135-144.

Levine, N., (1991). Semi-open sets and Semicontinuity in topological spaces, Amer. Math. 12: 5-13.

Mashhour, A.S., A.A. Allam, F.S. Mahmoud and F.H. Khedr, (1983). On supra topological spaces, Indian J. Pure and Appl.Math.14(A): 502-510.

Noiri, T. and O.R. Sayed, (2005). On $\Omega$ closed sets and $\Omega$ s closed sets in topological spaces, Acta Math., 4:307-318.

Vidyarani, L. and M. Vigneshwaran, (2013). NHomeomorphism and $\mathrm{N}^{*}$-Homeomorphism in supra topological spaces. Int. J. Math. Stat. Inv. 1(2): 79-83.

Vidyarani, L. and M. Vigneshwaran, (2013a). Some forms of N-closed maps in supra Topological spaces. IOSR J. Math. 6(4): 13-17.

Vidyarani, L. and M. Vigneshwaran, (2013b). On supra $\mathrm{N}$-closed and $\mathrm{sN}$-closed sets in supra Topological spaces. Int. J. Math. Arch. 4(2): 255259. 